\section{BRAZIULIAN JOURNAL}

OF MEDICAL AND BIOLOGICAL RESFARCH

www.bjournal.com.br
ISSN 0100-879X

Volume 43 (9) 812-913 September 2010

BIOMEDICAL SCIENCES

AND

CLINICAL INVESTIGATION

Braz J Med Biol Res, September 2010, Volume 43(9) 910-913

doi: 10.1590/S0100-879X2010007500079

Mutations of Bruton's tyrosine kinase gene in Brazilian patients with $\mathrm{X}$-linked agammaglobulinemia

V.D. Ramalho, E.B. Oliveira Júnior, S.M. Tani, P. Roxo Júnior and M.M.S. Vilela

The Brazilian Journal of Medical and Biological Research is partially financed by

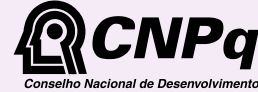

Ministério cientifico e Tecnológico

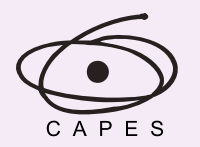

Ministério da Educação

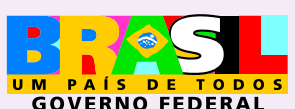

GOVERNO FEDERAL
DFAPESP

Institutional S ponsors

Hotsite of proteomics metabolomics developped by:

$$
\text { ana }
$$

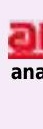




\title{
Mutations of Bruton's tyrosine kinase gene in Brazilian patients with X-linked agammaglobulinemia
}

\author{
V.D. Ramalho ${ }^{1}$, E.B. Oliveira Júnior ${ }^{1}$, S.M. Tani ${ }^{1}$, P. Roxo Júnior ${ }^{2}$ \\ and M.M.S. Vilela1 \\ ${ }^{1}$ Centro de Investigação em Pediatria, Departamento de Pediatria, Faculdade de Ciências Médicas, \\ Universidade Estadual de Campinas, Campinas, SP, Brasil \\ ${ }^{2}$ Departamento de Pediatria, Faculdade de Medicina de Ribeirão Preto, \\ Universidade de São Paulo, Ribeirão Preto, SP, Brasil
}

\begin{abstract}
Mutations in Bruton's tyrosine kinase (BTK) gene are responsible for X-linked agammaglobulinemia (XLA), which is characterized by recurrent bacterial infections, profound hypogammaglobulinemia, and decreased numbers of mature $B$ cells in peripheral blood. We evaluated 5 male Brazilian patients, ranging from 3 to 10 years of age, from unrelated families, whose diagnosis was based on recurrent infections, markedly reduced levels of $\operatorname{lgM}$, $\operatorname{lgG}$ and $\lg \mathrm{A}$, and circulating $\mathrm{B}$ cell numbers $<2 \%$. BTK gene analysis was carried out using PCR-SSCP followed by sequencing. We detected three novel (Ala347fsX55, I355T, and Thr324fsX24) and two previously reported mutations (Q196X and E441X). Flow cytometry revealed a reduced expression of BTK protein in patients and a mosaic pattern of BTK expression was obtained from mothers, indicating that they were XLA carriers.
\end{abstract}

Key words: X-linked agammaglobulinemia; Bruton's tyrosine kinase; Genome analysis; Brazilian patients

\section{Introduction}

X-linked agammaglobulinemia (XLA, MIM\# 300755) is a rare genetic disorder, which accounts for approximately $85 \%$ of patients with defects in early B cell development (1). XLA is characterized by a marked reduction in all serum immunoglobulin isotypes with significantly decreased or absent B cells, which causes susceptibility to recurrent and severe bacterial infections in affected males.

In 1993, the gene causing XLA was identified as Bruton's tyrosine kinase $(B T K)(2,3)$, which is localized on Xq21.3Xq22. BTK encompasses $37.5 \mathrm{~kb}$ containing 19 exons (4). $B T K$ encodes a multidomain protein composed of five different domains: proximal to the $N$-terminal there is a Pleckstrin homology $(\mathrm{PH})$ domain, followed by a Tec-homology $(\mathrm{TH})$, a Src-homology $3(\mathrm{SH} 3)$, Src-homology $2(\mathrm{SH} 2)$, and a tyrosine kinase domain (SH1) at the $C$-terminal (3).

More than 800 mutations in BTK have been described and have been found in all domains, being spread throughout the gene (http://bioinf.uta.fi/BTKbase) (5). Mutations in $B T K$ can be detected in $\sim 90-95 \%$ of males with presumed
XLA (1). Detection of a BTK mutation is necessary for a definitive diagnosis of XLA and subsequent genetic counseling.

The BTK mutations have been reported from many different regions (6). Our group has been the only one to publish the diagnosis of XLA by analysis of mutations of the BTK gene in Brazilian patients (7). In the present study, three new BTK mutations are described.

\section{Material and Methods}

\section{Subjects}

The patients with XLA presented in this study were diagnosed and treated with intravenous immunoglobulin replacement. XLA was diagnosed according to the recently updated criteria of a World Health Organization scientific group for primary immunodeficiency diseases (8): low levels of circulating B cells (measured by levels of CD19-positive cells in blood samples), decreased or absent immunoglobu- 
lins in serum, and a typical clinical history with recurrent bacterial infection or a positive family history. The study was approved by the Research Ethics Committee of the State University of Campinas (UNICAMP), Campinas, SP, Brazil, and all patients gave written informed consent to participate. Clinical characteristics, including the levels of immunoglobulins and B cell number, are described in Table 1.

\section{Flow cytometry analysis of BTK expression}

Expression of BTK protein was assessed by flow cytometry (9). Briefly, peripheral blood mononuclear cells (PBMC) were prepared from venous blood using FicollHypaque separation. The PBMC were first stained with a phycoerythrin-labeled anti-CD14 (IgG2a; Dako, Japan) MoAb to discriminate monocytes. These cells were fixed in $4 \%$ paraformaldehyde in phosphate-buffered saline for $15 \mathrm{~min}$ at room temperature, permeabilized in $0.1 \%$ Triton $\mathrm{X}-100$ for $5 \mathrm{~min}$, incubated with $2 \mu \mathrm{g} / \mathrm{mL}$ anti-BTK $(48-2 \mathrm{H})$ or control IgG1 (Dako) MoAbs for 20 min on ice, washed, and then further incubated with a 1:1000 dilution of fluorescein isothiocyanate-conjugated goat antimouse IgG1 antibody (Southern Biotechnology Associates, Inc., USA) for $20 \mathrm{~min}$ on ice. The stained cells were analyzed by flow cytometry (Epics XL-MCL flow cytometer, Beckman-Coulter, USA).

\section{Detection of $B T K$ mutations}

Genomic DNA was purified from venous blood with a Gentra Puregene Blood Kit (Qiagen, USA) and amplified with primers encompassing each exon-intron boundary of the BTK gene (10). The control samples were obtained from healthy adult volunteers. For single-strand conformation polymorphism (SSCP) analysis, the amplified products were electrophoresed on a polyacrylamide gel and visualized by SYBR Gold staining (Invitrogen, USA). When abnormal mobility was detected on the SSCP gel, the corresponding exons were sequenced by an automated MegaBACE
1000 genetic analyzer (GE Healthcare, USA). Because no abnormal mobility was detected on SSCP gels for patient 5 , we performed a new screening by SSCP using RT-PCRamplified products. Total RNA was extracted from PBMC with TRIzol Reagent (Invitrogen) and used for first-strand cDNA synthesis. PCR amplification of the cDNA involved seven overlapping primers (11).

\section{Results and Discussion}

All patients described in this study developed symptoms attributed to immunodeficiency during the first year of life and the major clinical manifestation was an increased susceptibility to respiratory tract infections. The main feature of XLA found in all patients was a marked reduction of B cells $(<1 \%)$ and hypogammaglobulinemia before intravenous immunoglobulin replacement, as shown in Table 1.

Flow cytometric evaluation of BTK expression in monocytes revealed a BTK deficiency (4.5 to $65.2 \%$ ) in all patients (Figure 1). A mosaic pattern of BTK expression in monocytes was observed for the mothers, indicating that they were XLA carriers. BTK mutations were detected in all patients by DNA sequencing.

In P1, a c.718C>T substitution created a stop codon (Q196X) in the TH domain, which contains a highly conserved $\mathrm{Zn}^{2+}$ binding motif and a polyproline stretch $(12,13)$. Mutations affecting the $\mathrm{Zn}^{2+}$ binding motif lead to the generation of unstable protein $(12,13)$. Similarly, the c.1453G $>\mathrm{T}$ substitution identified in $\mathrm{P} 4$ leads to premature termination of the protein (E441X) affecting the SH1 kinase domain. The kinase domain of BTK has approximately 250 residues and a three-dimensional model shows that at the center of its catalytic function there are binding sites for ATP and substrates that consist of highly conserved residues (14). Mutations in the kinase domain should stop the protein autophosphorylation activity $(9,15)$. Patients with mutations

Table 1. Clinical characteristics of our patients with X-linked agammaglobulinemia.

\begin{tabular}{|c|c|c|c|c|c|c|c|c|c|}
\hline \multirow[t]{2}{*}{ Patient No. } & \multirow{2}{*}{$\begin{array}{c}\text { Present } \\
\text { age }\end{array}$} & \multirow[t]{2}{*}{ Age at onset } & \multirow{2}{*}{$\begin{array}{c}\text { Age at } \\
\text { diagnosis }\end{array}$} & \multicolumn{3}{|c|}{ Ig levels $(\mathrm{mg} / \mathrm{dL})$ at diagnosis $\mathrm{b}$} & \multirow{2}{*}{$\begin{array}{c}\text { B cells } \\
(\%)\end{array}$} & \multirow[t]{2}{*}{ Mutation $^{\mathrm{c}}$} & \multirow[t]{2}{*}{ Clinical presentation } \\
\hline & & & & $\lg A$ & $\lg M$ & $\lg G$ & & & \\
\hline $\mathrm{P} 1$ & $3 y$ & $5 \mathrm{~m}$ & $11 \mathrm{~m}$ & $18(33-308)$ & $31(24-276)$ & $126(630-2000)$ & 0.1 & $718 \mathrm{C}>\mathrm{T}$ & Recurrent pneumonia \\
\hline $\mathrm{P} 2$ & $6 y$ & $3 \mathrm{~m}$ & 2 y $8 \mathrm{~m}$ & $1(90-450)$ & $22(28-212)$ & $149(750-1780)$ & 0 & 1204delT & $\begin{array}{l}\text { Recurrent pneumonia, } \\
\text { otitis media }\end{array}$ \\
\hline P3 & $7 y$ & $4 \mathrm{~m}$ & 1 y 10 m & $<5.5(90-450)$ & $19(28-212)$ & $133(750-1780)$ & 0.2 & $1227 \mathrm{~T}>\mathrm{C}$ & $\begin{array}{l}\text { Pneumococcal meningitis, } \\
\text { pneumonia, sepsis, } \\
\text { neurologic sequelae }\end{array}$ \\
\hline P4 & $8 y$ & $1 \mathrm{~m}$ & $1 \mathrm{y}$ & $5(90-450)$ & $4(28-212)$ & $3.7(750-1780)$ & 0 & $1453 \mathrm{G}>\mathrm{T}$ & $\begin{array}{l}\text { Cellulitis, otitis media, } \\
\text { arthritis, congenital hip } \\
\text { dislocation }\end{array}$ \\
\hline P5 & $10 y$ & $4 \mathrm{~m}$ & $2 y$ & $23(68-500)$ & $26(30-180)$ & $86(660-2120)$ & 0.15 & 1135ins T & $\begin{array}{l}\text { Recurrent pneumonia, } \\
\text { sinusitis }\end{array}$ \\
\hline
\end{tabular}

aAge at the start of intravenous immunoglobulin replacement. bData in parentheses are normal immunoglobulin levels. ${ }^{c}$ Numbering of nucleotide position refers to cDNA sequence (GenBank accession No. NM_000061). $y=$ years; $m=$ months. 

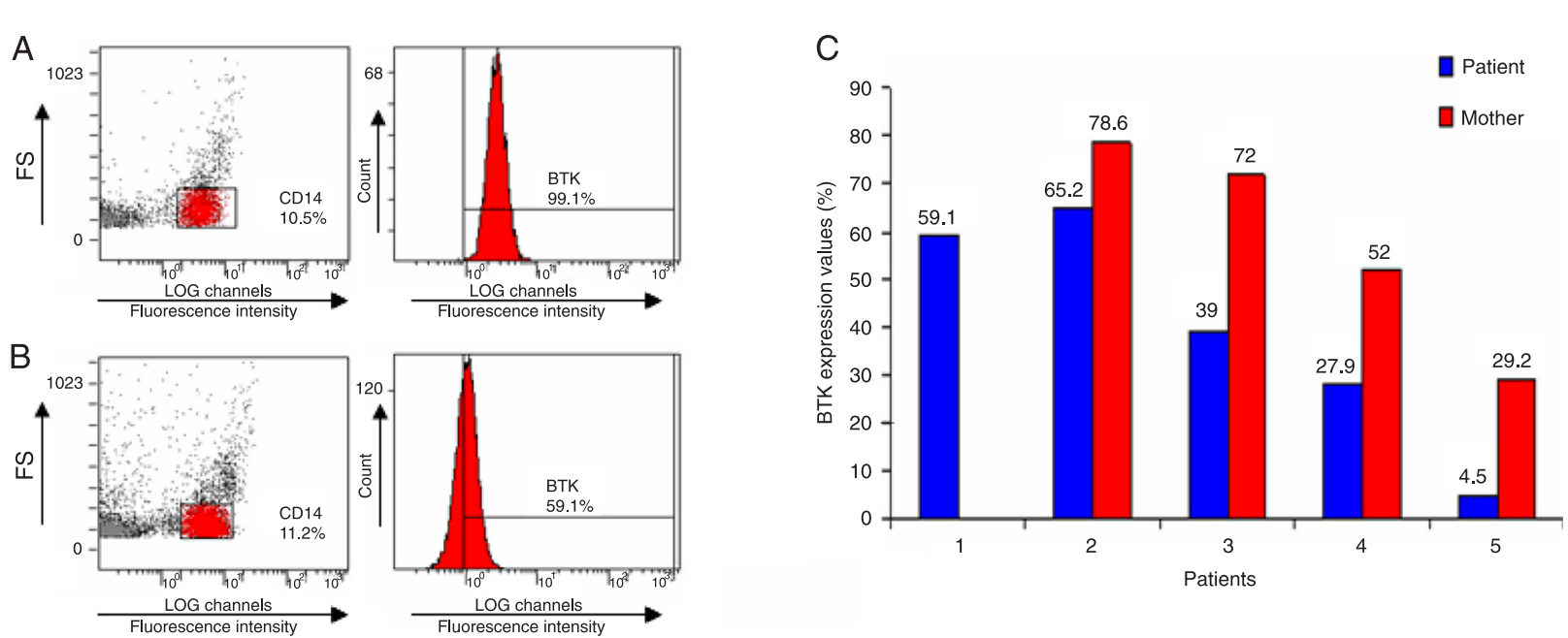

Figure 1. Bruton's tyrosine kinase (BTK) expression in patients with X-linked agammaglobulinemia (XLA). Flow cytometry analysis of monocyte BTK expression (gated on CD14+ cells) in a normal donor (A) and in a patient with XLA (B). The BTK expression for each patient and mother analyzed is presented as a histogram (C).

in $\mathrm{SH} 1$ and significant BTK expression have been reported by others (16).

Patients P2, P3, and P5 had mutations in the SH2 domain, which recognizes short peptide motifs bearing phosphotyrosine residues and links BTK to partner molecules (17). SH2 mutations should impair the BTK ability to induce calcium mobilization and flows from $B$ cell receptor stimulation (18). In P2, a c.1204delT deletion caused a frameshift mutation leading to a premature stop codon (Ala347fsX55). Similarly, in P5, a c.1135insT insertion resulted in the protein change Thr324fsX24. In P3, the c. $1227 \mathrm{~T}>\mathrm{C}$ mutation resulted in the amino-acid change 1355T. Due to the possibility of polymorphisms in the BTK gene, 100X-chromosomes were evaluated with $\mathrm{Bts} \mathrm{Cl}$ restriction enzyme (New England Biolabs, Inc., USA) for the c. $1227 \mathrm{~T}>\mathrm{C}$ substitution. Since the $\mathrm{c} .1227 \mathrm{~T}>\mathrm{C}$ mutation was not detected in the control samples, the mutation of P3 could be confirmed.

Identification of the molecular defect is an important tool for counseling family members at risk of being XLA carriers. Samples for carrier detection were obtained from three mothers, three grandmothers and 11 maternal aunts of patients in the study. All mothers analyzed presented heterozygous alleles for the mutations found in their sons,

\section{References}

1. Conley ME, Mathias D, Treadaway J, Minegishi Y, Rohrer J. Mutations in btk in patients with presumed X-linked agammaglobulinemia. Am J Hum Genet 1998; 62: 1034-1043.

2. Tsukada S, Saffran DC, Rawlings DJ, Parolini O, Allen RC, Klisak I, et al. Deficient expression of a B cell cytoplasmic tyrosine kinase in human X-linked agammaglobulinemia. Cell 1993; 72: 279-290. but only one grandmother (from P1) was a confirmed XLA carrier and none of the maternal aunts had mutations. According to Conley et al. (1), the mother of a patient with sporadic XLA has an $80 \%$ chance of being a carrier, but the maternal grandmother and the maternal aunt are carriers only 16 and $25 \%$ of the time, respectively. The lower frequency is due to the fact that most new mutations occur in male gametes $(19,20)$.

We identified five mutations in $B T K$ during the course of our study. Mutations Q196X (P1) and E441X (P4), have been reported previously; the remaining three -Ala347fsX55(P2), I355T (P3), and Thr324fsX24(P5) - are new. The mutations identified lead to deficiency in BTK expression reflecting a reduction of mRNA or the instability of protein produced. The combined use of genetic analysis and flow cytometric assay of BTK protein expression allowed the definitive diagnosis of XLA and its detection in carriers.

\section{Acknowledgments}

We are grateful to all families for their generous co-operation. Research supported by FAPESP (\#2008/54220-3). V.D. Ramalho was the recipient of a CAPES fellowship. E.B. Oliveira Júnior was the recipient of a FAPESP fellowship.

3. Vetrie D, Vorechovsky I, Sideras P, Holland J, Davies A, Flinter $F$, et al. The gene involved in $X$-linked agammaglobulinaemia is a member of the src family of protein-tyrosine kinases. Nature 1993; 361: 226-233.

4. Ohta Y, Haire RN, Litman RT, Fu SM, Nelson RP, Kratz J, et al. Genomic organization and structure of Bruton agammaglobulinemia tyrosine kinase: localization of mutations 
associated with varied clinical presentations and course in $X$ chromosome-linked agammaglobulinemia. Proc Natl Acad Sci U S A 1994; 91: 9062-9066.

5. Mohamed AJ, Yu L, Backesjo CM, Vargas L, Faryal R, Aints $A$, et al. Bruton's tyrosine kinase (Btk): function, regulation, and transformation with special emphasis on the $\mathrm{PH}$ domain. Immunol Rev 2009; 228: 58-73.

6. Toth B, Volokha A, Mihas A, Pac M, Bernatowska E, Kondratenko I, et al. Genetic and demographic features of Xlinked agammaglobulinemia in Eastern and Central Europe: a cohort study. Mol Immunol 2009; 46: 2140-2146.

7. Tani SM, Wang Y, Kanegane H, Futatani T, Pinto J, Vilela $\mathrm{MM}$, et al. Identification of mutations of Bruton's tyrosine kinase gene (BTK) in Brazilian patients with X-linked agammaglobulinemia. Hum Mutat 2002; 20: 235-236.

8. Primary immunodeficiency diseases. Report of a WHO Scientific Group. Clin Exp Immunol 1995; 99 (Suppl 1): 1-24.

9. Futatani T, Miyawaki T, Tsukada S, Hashimoto S, Kunikata T, Arai S, et al. Deficient expression of Bruton's tyrosine kinase in monocytes from X-linked agammaglobulinemia as evaluated by a flow cytometric analysis and its clinical application to carrier detection. Blood 1998; 91: 595-602.

10. Vorechovsky I, Vihinen M, de Saint Basile G, Honsova S, Hammarstrom L, Muller S, et al. DNA-based mutation analysis of Bruton's tyrosine kinase gene in patients with X-linked agammaglobulinaemia. Hum Mol Genet 1995; 4: 51-58.

11. Hashimoto S, Tsukada S, Matsushita M, Miyawaki T, Niida Y, Yachie A, et al. Identification of Bruton's tyrosine kinase (Btk) gene mutations and characterization of the derived proteins in 35 X-linked agammaglobulinemia families: a nationwide study of Btk deficiency in Japan. Blood 1996; 88: 561-573.

12. Hyvonen M, Saraste M. Structure of the PH domain and Btk motif from Bruton's tyrosine kinase: molecular explanations for X-linked agammaglobulinaemia. EMBO J 1997; 16:
3396-3404

13. Vihinen M, Nore BF, Mattsson PT, Backesjo CM, Nars M, Koutaniemi S, et al. Missense mutations affecting a conserved cysteine pair in the TH domain of Btk. FEBS Lett 1997; 413: 205-210.

14. Vihinen M, Vetrie D, Maniar HS, Ochs HD, Zhu Q, Vorechovsky I, et al. Structural basis for chromosome X-linked agammaglobulinemia: a tyrosine kinase disease. Proc Natl Acad Sci U S A 1994; 91: 12803-12807.

15. Gaspar HB, Lester T, Levinsky RJ, Kinnon C. Bruton's tyrosine kinase expression and activity in X-linked agammaglobulinaemia (XLA): the use of protein analysis as a diagnostic indicator of XLA. Clin Exp Immunol 1998; 111: 334-338.

16. Gaspar HB, Ferrando M, Caragol I, Hernandez M, Bertran $\mathrm{JM}$, De Gracia X, et al. Kinase mutant Btk results in atypical X-linked agammaglobulinaemia phenotype. Clin Exp Immunol 2000; 120: 346-350.

17. Valiaho J, Smith Cl, Vihinen M. BTKbase: the mutation database for X-linked agammaglobulinemia. Hum Mutat 2006; 27: 1209-1217.

18. Guo S, Wahl MI, Witte ON. Mutational analysis of the SH2kinase linker region of Bruton's tyrosine kinase defines alternative modes of regulation for cytoplasmic tyrosine kinase families. Int Immunol 2006; 18: 79-87.

19. Carlson KM, Bracamontes J, Jackson CE, Clark R, Lacroix $A$, Wells $S A ~ J r$, et al. Parent-of-origin effects in multiple endocrine neoplasia type 2B. Am J Hum Genet 1994; 55: 1076-1082.

20. Tuchman M, Matsuda I, Munnich A, Malcolm S, Strautnieks $\mathrm{S}$, Briede T. Proportions of spontaneous mutations in males and females with ornithine transcarbamylase deficiency. Am J Med Genet 1995; 55: 67-70. 